\title{
A publicidade como ação coletiva: agências, modelos de negócios e campos profissionais ${ }^{1}$
}

\author{
Everardo Pereira Guimarães ROCHA ${ }^{2}$ \\ Bruna Santana AUCAR ${ }^{3}$
}

\begin{abstract}
Resumo:
Este trabalho analisa a constituição do campo publicitário a partir do aparecimento de empresas que organizam modelos produtivos e identidades profissionais em torno de ações coletivas. Parte-se da premissa de que a agência foi a instituição responsável por traçar as condições de existência de um segmento, até então inexistente. $\mathrm{O}$ estudo concentra-se no exame das primeiras disposições profissionais instituídas pelas agências entre meados do século XIX e início do século XX nos Estados Unidos e Europa e a posterior reprodução desse padrão de negócios no Brasil. Assim, procura-se realçar, com o percurso histórico dessas agências pioneiras, o surgimento de funções profissionais e suas formas de atuação conjugadas para o reconhecimento social da publicidade.
\end{abstract}

Palavras-chave:

Agências. Ação coletiva. Campo. Howard Becker. Eclética.

\section{Advertising as a collective action: agencies, business models and professional fields}

\begin{abstract}
:
This paper analyzes the constitution of the advertising field from the birth of companies that organize productive models and professional identities around collective actions. It is based on the premise that the agency was the institution responsible for outlining the conditions for the existence of a segment, which had never existed before. This study concentrates on the examination of the first professional dispositions instituted by the agencies between the mid-nineteenth and early twentieth centuries in the United States and Europe and the subsequent reproduction of this pattern of business in Brazil. Thus, it is sought to highlight, with the historical path of these pioneer agencies, the emergence of professional functions and their forms of action combined for the social recognition of advertising field.
\end{abstract}

Keywords: Agencies. Collective Action. Professional field. Howard Becker. Eclética.

\section{La publicidad como acción colectiva: agencias, modelos de negocios y campos profesionales}

\section{Resumen:}

Este trabajo analiza la constitución del campo publicitario a partir de la aparición de empresas que organizan modelos productivos e identidades profesionales en torno a acciones colectivas. Se parte de la premisa de que la agencia fue la institución responsable de trazar las condiciones de existencia de un segmento, hasta entonces inexistente. El estudio se centra en el examen de las primeras disposiciones profesionales instituidas por las agencias entre mediados del siglo XIX y principios del siglo XX en los Estados Unidos y Europa y la

\footnotetext{
${ }^{1}$ Este trabalho é uma versão revista e ampliada de artigo apresentado no COMUNICON 2018 - Congresso Internacional em Comunicação e Consumo, São Paulo, 2018.

${ }^{2}$ Everardo Rocha é doutor pelo Museu Nacional UFRJ. Professor associado e coordenador de pesquisa do Departamento de Comunicação Social da PUC-Rio. E-mail: everardo@puc-rio.br integra o Grupo de Pesquisa Mediações e Interações Radiofônicas.E-mail: lorenahang@gmail.com.

3 Bruna Aucar é doutora pelo Programa de Pós-graduação em Comunicação da PUC-Rio. Professora do Departamento de Comunicação Social da PUC-Rio. E-mail: aucar@puc-rio.br
} 
posterior reproducción de ese patrón de negocios en Brasil. Así, se pretende realzar, con el recorrido histórico de esas agencias pioneras, el surgimiento de funciones profesionales y sus formas de actuación conjugadas para el reconocimiento social de la publicidad.

Palabras clave:

Agencias. Acción Colectiva. Campo. Howard Becker. Eclética.

\section{O anúncio como ação coletiva}

Os muitos comunicados relacionados ao comércio ou aos assuntos públicos em geral - reclames, anúncios, classificados, relatos, decretos e o que mais se queira - foram colocados para circular socialmente em diferentes momentos da história e localizações no espaço. Para alguns, avisos colados ou lidos em voz alta no Fórum Romano, gritos de comerciantes na rota da seda, pregões nos mercados do Oriente, arautos de um senhor feudal qualquer na Europa medieval, classificados da venda de fazendas no Brasil imperial ou comunicados sobre fugas de escravos no Egito antigo (MALANGA, 1976) podem ser apontados como aquilo que viria a ser, a partir do século XVIII, o que chamamos publicidade ${ }^{4}$.

É claro que esse raciocínio possui um viés etnocêntrico e evolucionista que tende a perceber tudo na existência humana como um simples embrião, um modo precário ou errado de fazer o que fazemos hoje (LÉVI-STRAUSS, 1973 [1952]). Uma boa forma de reafirmação do que somos e dos nossos "acertos" como sociedade é explicar que os antepassados "antigamente" tentavam e não sabiam ou não conseguiam. Nosso "progresso" os ensinou. E, portanto, existe uma espécie de "genealogia heroica" a sustentar muitas das nossas atividades profissionais (ROCHA, 1985). O passado, próximo ou distante, sempre pode oferecer um material de grande maleabilidade ideológica que tanto pode ser usado para negá-lo completamente como "errado" ou "mal" quanto afirmá-lo como "esforço incipiente" e "bom" que, porém, só conosco deu certo. Nesse sentido, o passado pode explicar quase tudo o que quisermos sobre o presente. Assim, muitas das visões ou explicações sobre as "origens" de certos fenômenos, ocupações, práticas ou profissões que encontramos no mundo de hoje se devem aos esforços em procurar um "passado mítico" que as sustente e legitime. No entanto, não é preciso entrar nessa discussão de "origens" ou "determinações" para entender que a organização da atividade em agências foi a instância responsável pelos arranjos profissionais e pelo reconhecimento

\footnotetext{
${ }^{4}$ Os termos "publicidade" e "propaganda" serão usados como sinônimos por uma questão de estilo. Em todo o trabalho, referem-se às mensagens produzidas por agências e veiculadas em espaços pagos sob a chancela de um anunciante identificado.
} 
social que deram lugar ao que chamamos de publicidade no mundo modernocontemporâneo.

O objetivo deste trabalho é, portanto, demonstrar que a agência Eclética, criada em 1914, foi um acontecimento central para a constituição do campo publicitário no Brasil. As condições de existência desse setor são resultado e expressão de tipos de interação social e ação coletiva que acontecem mediados pelas agências e, sobretudo, dentro delas e a partir delas, conforme indica a teoria da ação coletiva de Howard Becker (1977a). Ou seja, uma boa referência para pensar a publicidade e seus impactos na cultura modernocontemporânea é o exame dessas instâncias que organizaram uma atuação conjunta e coordenada de identidades cuja colaboração é necessária para que o trabalho aconteça. Para tanto, é necessário mostrarmos que tais processos de estabelecimento de normas profissionais, especialização de funções, modos operacionais, regulamentos, formação de associações e reflexões críticas sobre o campo se iniciam entre meados do século XIX e início do século XX a partir das primeiras agências nos Estados Unidos e na Europa e a consequente reprodução desse modelo no Brasil.

Seguindo essa perspectiva interacionista, podemos dizer que algo se define quando identidades e organizações se mesclam na realização de determinadas ações para a existência de acontecimentos e produtos específicos e próprios de tal "mundo". Seja qual for o objeto, ele é demarcado pelo conjunto de agentes sociais que realizam atividades correlacionadas para essa produção aparecer: "Toda atividade é o trabalho de alguém. Isso quer dizer que para compreender uma atividade, qualquer que seja, é necessário pesquisar junto às pessoas para quem aquela atividade é um trabalho.” (BECKER, 2013, p. 132). São as atividades coletivas humanas, em permanentes negociações de significados e poderes, que criam os produtos sociais e as marcações identitárias, bem como as estruturas que proporcionam os sistemas de criação desses produtos e identidades.

Becker (1977a) sugere que estratégias de interação e rituais são elementos básicos para compreender processos sociais, destacando atores e encadeamento de eventos como modeladores de um determinado sistema cultural. As atividades que conhecemos envolvem a divisão do trabalho com seus circuitos elaborados de colaboração. No processo de composição, seja de uma representação seja de um artefato, é preciso uma cadeia de tarefas e um concatenamento de atos propositivos. Os atores que produzem os anúncios dentro de uma agência de propaganda, seus elos cooperativos e redes de convenções, por exemplo, são encadeamentos necessários para materializar esse tipo de comunicação. 
A publicidade se estabelece como uma profissão do nosso tempo, a partir de certas condições que foram determinantes para demarcar um campo e uma produção material e simbólica específica. O desenvolvimento do capitalismo, a inovação tecnológica, o crescimento da vida nas cidades, a expansão do mercado consumidor e dos meios de comunicação a partir da virada do século XVIII para o XIX proporcionaram a organização de novas cadeias de atividades profissionais.

As agências se materializaram propiciando o aparelhamento necessário que associou os elementos para o vir a ser do anúncio publicitário como parte do processo produtivo capitalista. Foram essas organizações empresariais que arregimentaram pessoas, interações e convenções que demarcaram a profissão de publicitário, suas representações, práticas e reconhecimento social e jurídico. A teoria da ação coletiva mostra que o comportamento de indivíduos ou grupos, valores morais, estereótipos, bem como a criação de estruturas ou instituições sociais são resultados de mecanismos de interação, elos estabelecidos socialmente, redes que colocam atores em conexão e interdependência. Assim, a consequência concreta dos fazeres individuais acontece como um resultado dos mecanismos de troca, dos espaços de convívio e dos artifícios de vinculação institucional. As identidades são concebidas como a internalização dos processos socialmente construídos em cada espaço e momento histórico, os comportamentos são arquitetados no discurso da ação. "Podemos descrever os membros dos diversos mundos adotando como critério o grau em que participam ou dependem dos comportamentos regulares que constituem a ação coletiva do mundo a que pertencem e dos quais dependem do resultado desta ação" (BECKER, 1977b, p. 11).

A publicidade é um discurso que projeta uma interpretação da realidade, que articula e hierarquiza bens e pessoas, visando o acontecimento do consumo. Dos "tempos heroicos da propaganda" 5 ao tempo presente dessa poderosa indústria, a publicidade se instituiu por meio da construção de códigos culturais que atuaram como parte do processo de criação de significados na cultura (WAGNER, 2010). Interpretar a trajetória da publicidade, a partir da formação de suas agências, é uma tentativa de compreender que, ao menos em parte, os anúncios, como resultado socialmente compartilhado, tem por base a

\footnotetext{
${ }^{5}$ No livro raro Os tempos heroicos da propaganda, o autor Genival Rabelo (1956) publica reportagens feitas para a revista $P N$ - Política \& Negócios sobre as agências pioneiras. Nas principais publicações sobre o segmento, convencionou-se chamar de "tempos heroicos da propaganda", entre 1914 e 1935, o período de fundação das agências mais antigas do Brasil.
} 
construção de um campo, sua organização empresarial, sua divisão de papeis e seu posterior reconhecimento público.

\section{Encaixe de peças e campo profissional}

As primeiras agências de publicidade nos Estados Unidos surgem no período que foi chamado por Karl Polanyi de "cem anos de paz". Seu importante estudo, A grande transformação (2012 [1944]), define o ciclo localizado entre 1815 e 1914 como um tempo pacífico, sem maiores conflitos entre as grandes potências. O crescimento econômico e o bom relacionamento entre os países traziam a aparência de uma relativa prosperidade, com um cenário favorável aos negócios, expansão das capacidades industriais e aceleração da circulação de mercadorias e trocas comerciais.

O mercado se interessava em demasia pela paz e praticava uma política distinta da executada em momentos anteriores da história, quando a organização comercial era baseada em guerras, conflitos, armadilhas, lutas corporais e tinha como personagens figuras como exploradores, conquistadores e mercadores de escravos. Durante os "cem anos de paz", os grandes comerciantes e industriais perceberam que esse clima era bom para os negócios, pois estimulava transações internacionais, contribuía para a expansão dos mercados e fazia com que as pessoas ocupassem o espaço público e gastassem rapidamente o dinheiro que ganhavam (ROCHA; FRID; CORBO, 2016).

Nos Estados Unidos, França, Alemanha e Inglaterra existiam agências desde meados do século XIX. A expressão Advertising Agency foi possivelmente usada pela primeira vez por Volney Palmer, na Filadélfia (PINCAS; LOISEAU, 2008). Sua empresa, em 1842, criava anúncios e instituiu a cobrança de comissão aos jornais para vender espaço publicitário (PINCAS; LOISEAU, 2008). A elaboração de um modelo de negócios padronizado e rotineiro começa então a fornecer as bases para a demarcação do mundo da publicidade. A institucionalização de retribuição financeira já articula uma relação entre operadores desse mercado - a agência, o jornal e o cliente - em conexão e interdependência. A legitimidade do campo é promovida pelos próprios agentes sociais em conjunto que criam e colocam em circulação certos tipos de condutas, normatividades, comportamentos, termos e identidades (BECKER, 1977a). Uma vez estabelecidas, são como que apagadas as relações de poder que as originaram e a percepção dominante que governa as práticas no campo passa a ser mais evidenciada, naturalizada (BOURDIEU, 1983). A simples adoção de uma comissão por vendagem, estipulada não por atores sociais 
singulares, mas por uma instituição empresarial, começa a organizar os pressupostos que iriam reger a atividade publicitária, antes dispersos e desorganizados, o que embaçava ou até impedia o reconhecimento do campo.

A iniciativa de Palmer desperta a confiabilidade e congrega outros atores sociais que assumirão uma força específica dentro do universo da publicidade, ocupando uma "posição relativa" no espaço. Seguindo as análises de Bourdieu (1983) sobre o poder simbólico construído nos diferentes espaços sociais, podemos dizer que o conjunto de forças objetivas do campo é imposto a todos os agentes, inflexível aos desígnios individuais. Dessa forma, os pioneiros são muitas vezes os responsáveis por estabelecer regras institucionais, princípios e formas de ação inovadores, estéticas próprias, significados e relações de poder.

Assim, cerca de duas décadas após as regras de remuneração que viabilizam os financiamentos do negócio, um novo marco na regulação do mundo publicitário é estabelecido. A N.W. Ayer \& Son, fundada em 1869, foi a primeira agência a se responsabilizar pelo conteúdo dos anúncios e introduzir o contrato aberto, que mudou o mercado da publicidade em definitivo (HOWER, 1978). O Open Contract garantia preços mais baixos possíveis aos clientes nos espaços da imprensa. Sobre esse preço era cobrada uma comissão que variava entre 8,5 e 15\%. A partir de 1909, o "contrato aberto" ficou conhecido como "O.C. $+15 \%$ ” de comissão da agência. O modelo se tornou mais tarde o padrão das transações publicitárias (HOWER, 1978).

A Ayer é considerada uma das agências mais influentes na formação do campo publicitário (HOWER, 1978). Com ela, surge também a dimensão de um "saber", algo absolutamente fundamental no processo de consolidação do campo. Foi a Ayer que publicou os textos - Ayer \& Son's Manual for Advertisers e The Advertiser's Guide (HOWER, 1978) - que organizaram funções, catalogaram espaços de veiculação, definiram papéis e apresentaram reflexões e conhecimentos sobre o mundo publicitário. Tais procedimentos montaram uma espécie de cartilha da fabricação de anúncios, que serve não apenas para a materialização da produção, como também para a construção das identidades profissionais. A representação do papel de cada ator social se dá, inclusive, fora da esfera da agência e se compõe como identidade cultural, como sugere Becker (1977a).

Cada agente, na esfera de sua identidade profissional, pôde colocar em prática uma competência característica, elaborada pelas convenções de seu setor, para que o anúncio 
fosse construído de forma conjugada e aparecesse sólido socialmente. O sucesso do sistema e a fabricação de um produto são decorrentes da articulação das identidades individuais projetadas dentro de uma agência, suas ligações cooperativas através de circuitos integrados.

Com o lançamento de publicações, a Ayer acionou mecanismos essenciais de legitimação do campo. Manuais, livros, edições, guias, boletins, periódicos são objetos materiais de imensa força simbólica, uma vez que estão associados ao conhecimento, à informação e à educação, o que gera sempre discursos nobres e positivos em relação a esses artefatos. Há ainda o sentido de propagador cultural, componente que transcende o espaço e o tempo, inscrevendo os conteúdos das publicações em um imaginário socialmente compartilhado e na própria história. Escritos sobre a operacionalização de uma agência de publicidade enobreceram as representações sociais desses profissionais, garantiram seu reconhecimento e prestígio, contribuíram para a gênese histórica do setor, além de terem sido a pedra angular para validar essas práticas como um "saber" de nível universitário (ROCHA, 1985). Muitos desses escritos ainda permanecem como referências para perpetuar representações glamourizadas da profissão, servindo inclusive de aporte teórico e material didático das universidades. No entanto, tais narrativas muitas vezes não correspondem a atual realidade do campo, impactado com as dinâmicas da comunicação digital, sobrecargas de trabalho, discriminações de gênero e ambientes de imensa pressão profissional.

Em 1878 é inaugurada a $J$. W. Thompson, após a compra da agência Carlton \& Smith, em Nova Iorque (J. WALTER THOMPSON, 2014). No fim do século XIX, com a aceleração da Revolução Industrial e o desenvolvimento de economias mais produtivas, a $J W T$, sigla pela qual a empresa ficou conhecida, soube aproveitar oportunidades e ajudar diversos comerciantes em seus objetivos de venda. No período que vai do fim dos anos 1870 até a década de 1910 houve uma rápida industrialização nas cidades americanas, com inovações científicas, tecnológicas e o crescimento de grandes companhias (POLANYI, 2012 [1944]). Às vésperas do novo século, a JWT decide contratar escritores e artistas para incrementar a propaganda dessas empresas em franca ascensão e ajudar a vender mais espaços nos jornais (PENTEADO, 2004). Este foi um movimento marcante de legitimação do campo publicitário, uma vez que começa a percepção de que o negócio deveria incorporar ideias criativas para impulsionar vendas. Nasce um esboço do Departamento de Criação e, com ele, a elaboração de anúncios mais complexos. 
O modelo, que explorava a criatividade na veiculação das mensagens comerciais, fez com que a atividade publicitária ganhasse expansão, aprimoramento e, principalmente, o glamour necessário para sua visibilidade sociocultural. Profissionais refinaram suas técnicas, e critérios rigorosos de qualidade foram elaborados nas décadas seguintes em várias partes do mundo. Dessa maneira, a $J W T$ delineia o sistema hierárquico que prevalece até hoje na divisão profissional das agências (PENTEADO, 2004). De acordo com Knoploch (1980), a área da criação é tida como centro da empresa, o setor que alimenta os demais, o responsável por uma reunião de ações e sua interdependência. É o departamento mais prestigiado e de mais altos salários. A mitologia profissional indica que é preciso um "talento" especial, um dom "sublime” para exercer essa prática (ROCHA, 1985). Por isso, há uma inclinação dos demais segmentos em atender suas demandas, uma vez que a integralidade do negócio estaria dependente da aptidão criativa. É importante observar que o profissional de criação é também o mais cobrado pelos resultados da agência, o que resulta em acumulo de funções, rotinas de estresse e tensão, disponibilidade integral para o trabalho, o que inclui dedicação à conquista e manutenção de clientes, dentro e fora da agência.

A projeção de um departamento específico para produzir um tipo de ação singular foi indicativa das futuras disposições profissionais em torno de seções que realizam atividades independentes e interligadas. As agências desde então contam com um modelo ou padrão básico de quatro divisões principais - Atendimento, Planejamento, Mídia e Criação - capazes de diferenciar uma empresa de publicidade dos demais empreendimentos do mundo corporativo. Cada ramificação aglutina agentes que concebem o trabalho, o executam, fornecem equipamentos e materiais e ordenam os canais de divulgação para o público que consumirá a mensagem. Juntos, esses setores formam uma rede cooperativa determinante para a materialização do anúncio. Esses elos colaborativos seguem uma rotina de afazeres definida pelas convenções do campo publicitário. Ou seja, para que um anúncio se concretize, as agências seguem uma cadeia de tarefas interpostas em fases ou processos de produção regrados.

O desempenho corporativo da $J W T$ se alarga, então, no sentido de novos mercados e outros países. A abertura da filial de Portugal contou com a colaboração do poeta Fernando Pessoa. É do escritor a célebre frase publicitária "primeiro estranha-se, depois entranha-se", criada para a campanha da Coca-Cola, em 1928, o que fez as vendas dispararem (ALMEIDA, 1954). Em 1927, a JWT abre os primeiros escritórios no Egito e 
na África do Sul (J. WALTER THOMPSON, 2014). É o início do processo de internacionalização do empreendimento publicitário e o campo se consolida em definitivo. O mundo começa não só a saber que existe, como também o que é a publicidade pelas agências norte-americanas que definem e exportam o modelo de negócios para muitos países, inclusive o Brasil, como veremos adiante. A constituição de novas agências de publicidade em outros lugares aglutina elementos da prática, porventura ainda dispersos, com normatividades e papéis bem definidos, metodologias de trabalho, vínculos com os espaços de comunicação e reflexões sobre seus processos produtivos. Definiam-se os alicerces do segmento e a imagem de profissionalismo e aparelhamento necessários ao setor. Como de resto acontece com qualquer campo de atividades ou práticas sociais, essas empresas desenvolveram formas padronizadas de apoio, significados convencionais que sustentaram um sistema de representações.

\section{Publicidade à brasileira}

A Eclética, primeira agência brasileira, já foi fundada, em maio de 1914 em São Paulo, com o sentido de um campo próprio de trabalho e a estrutura de um modelo de negócios. Reunia, portanto, as premissas necessárias - remuneração definida, modelo de contrato, responsabilidade pelo que anunciava, definição de atividades e funções, coleção de saberes - para a existência do campo publicitário no país. A empresa, embora criando mensagens persuasivas, atuava, principalmente, como uma corretora de anúncios em jornais, sendo determinante para a certificação social da publicidade no Brasil.

A mais antiga agência de propaganda nacional era de propriedade do empresário Jocelyn Benaton e do jornalista João Castaldi (RABELO, 1956). O modelo de negócios que supunha a relação entre cliente, agência e veículo precisava se impor no contexto de um novo mercado, o brasileiro, não maduro ainda para um claro entendimento do que vinha sendo feito, há mais de meio século, em capitalismos mais avançados. Não por acaso, um dos movimentos da Eclética foi explicar a si mesma e a natureza de seu negócio em anúncios de jornal. Em um anúncio, a imagem que remete ao "Pensador" de Rodin é acompanhada do seguinte texto:

Reflicta antes de pôr em execução o seu plano de propaganda. A propaganda é efficaz quando bem feita o distribuída com criterio, evitando gastos inuteis. É preciso ter sempre em vista a tiragem do jornal, meio em que circula, modo de confeccionar o anunncio, disposição e logares em que o producto possa ser lançado. Portanto, é previdente todo o negociante que deseja augmentar seus negócios consultar sobre este 
assunpto a Empresa de Publicidade "A Eclética", à rua Boa Vista, 24. (REFLICTA..., 1925, p. 16). ${ }^{6}$

Figura 1 - Anúncio A Eclética

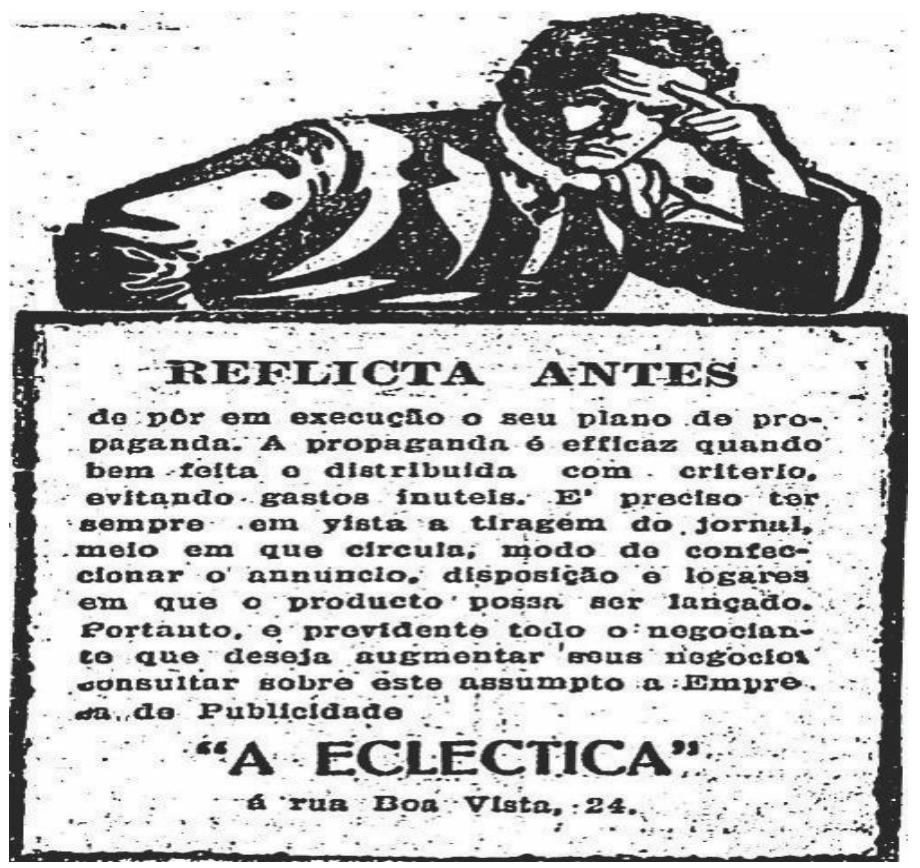

Fonte: Acervo on-line do jornal O Estado de S. Paulo, 26 de fevereiro de 1925, p. 16.

Antes do aparecimento das agências, eram os próprios veículos de comunicação que vendiam seus espaços diretamente, modelo que continua vivo em algumas cidades do interior. A imprensa era bastante pobre em publicidade e dependia de vínculos políticos (BARBOSA, 2007).

O processo de publicação de anúncios funcionava de maneira informal. Em geral, um comerciante concordava em anunciar em jornais quando considerava o corretor bom sujeito ou indicado por político influente. A propaganda era rudimentar e o corretor um inconveniente solicitante, vendendo o que não era necessário comprar. Alguns estabelecimentos colocavam até avisos do tipo: "Esta casa não dá esmolas e não atende gente de publicidade" (RABELO, 1956, p. 92).

Com as primeiras empresas de publicidade, os clientes e os jornais começaram a perceber que a participação de mediadores no processo traria prosperidade para as vendas. Além disso, as agências brasileiras procuraram estabelecer a identidade cultural da profissão de publicitário distante da figura do corretor. A atividade, antes marginalizada como ofício menor ou mesmo não percebida como tal nas primeiras décadas do século XX, 
ganha, pouco a pouco, uma posição social estabelecida e com ela status e prestígio (ROCHA, 1985). Assim, a Eclética estrutura o agenciamento de anúncios para os jornais, como O Estado de S. Paulo, e se estabelece no Rio de Janeiro a partir de 1918 (RABELO, 1956).

Nos primeiros anos, a Eclética atua negociando espaços na imprensa, porém, no mesmo compasso do desenvolvimento dos mercados e da estruturação do campo publicitário, consegue as contas mais importantes do mercado, entre elas a da Ford Motor Co. e a da Texaco (ABREU; PAULA, 2007). Com a conquista da conta da Ford, em 1925, a Eclética engendra uma cadeia de ações e redes de dependência que integra diversos agentes até então desarticulados. Os elos colaborativos e atividades relacionadas foram centrais para que o anúncio fosse percebido como uma narrativa relevante no Brasil. A Eclética foi a primeira a materializar essa ação conjunta ao elaborar dispositivos, normas, saberes e técnicas produtivas com base nos padrões pré-existentes no mercado norteamericano.

A moderna estratégia de comunicação da Ford incluiu anúncios também em jornais do interior, uma vez que a empresa tinha concessionárias espalhadas pelo país. O receio dos proprietários desses jornais em relação à "gente de publicidade" dificultou o contato e a entrada da agência no interior. Para que as comunicação da empresa tivesse sucesso, os publicitários precisavam viajar pelo Brasil para tentar convencer donos de jornais de que a publicidade era algo promissor e capaz de aumentar suas receitas (RABELO, 1956). Para vencer as dificuldades, uma iniciativa foi importante: a criação, em parceria com a Ford, de um sistema de premiação aos agentes por carro vendido (RABELO, 1956).

Cada conjunto de regras que formata uma nova maneira de atuação em um espaço social ocasiona uma remodelação de comportamentos e linguagens do campo. Os processos produtivos são modificados e outras convenções estabelecidas para lidar com as novas propostas, funções, aparatos, ferramentas e recursos (BECKER, 1977b). Nesse sentido, os agentes que antes estavam acostumados com um modelo de ação social encontram-se diante do desafio de promover adaptações de condutas e papéis, o que traz consequências para suas disposições subjetivas e culturais (BECKER, 1977b).

Muitas vezes, é preciso deixar para trás as antigas convenções e aprender a lidar com os novos equipamentos e materiais. Profissionais e agentes sociais que não se adaptarem podem ter seu capital simbólico ameaçado e perder seu prestígio, assim como aqueles que se adequarem com facilidade podem ter ganhos ou mesmo galgar posições 
hierárquicas, seja em um meio particular seja no próprio espaço social como um todo (BOURDIEU, 1983). A alteração de uma convenção também transforma a percepção da estética de um campo, além de ampliar as possibilidades de atuação e emprego de novos profissionais (BECKER, 1977a).

Tais implicações podem ser facilmente observadas com as complexas dinâmicas trazidas ao campo da publicidade pelos meios digitais. Hoje, o publicitário precisa achar soluções multimídia para os diferentes problemas de comunicação de seus clientes, o que demanda aprendizado ininterrupto e altos investimentos em aperfeiçoamento técnico. As rápidas e constantes mudanças tecnológicas também fizeram com que jovens não vocacionados, sem formação profissional ou oriundos de outras áreas de conhecimento passassem a atuar no setor, aumentando assim a concorrência e ameaçando o emprego de profissionais reconhecidos. A estrutura institucional das agências também se vê ameaçada, uma vez que o ambiente on-line originou outros modelos de negócios, como as startups ou empresas que não necessitam de espaço fixo e contratam profissionais temporários, de acordo com a demanda de trabalho.

Após a instalação e consolidação dos primeiros mercados no Brasil, a Eclética vai buscar, nos mesmos moldes da JWT anos antes, visibilidade no mercado externo, não só para conquistar clientes em outros países, como também para adquirir status, importante capital simbólico de um negócio em processo de estruturação.

Além da Ford e da Texaco, a Eclética atendeu as contas mais importantes das primeiras décadas do século XX, como Shering, Sabonetes Eucalol, Biscoitos Aymoré, Chocolate Lacta, Guaraná Espumante, Indústria Matarazzo e Westinghouse. Para a Texaco, elaborou mapas das principais estradas brasileiras, com a sinalização de seus postos de gasolina (REIS, 1990). Com a Eclética, vários atores do mercado comerciantes, empresários, farmacêuticos, financistas, industriais, leiloeiros - começaram a descobrir o poder da publicidade em processo de legitimação. De fato, trata-se do movimento de consolidação de um modelo de negócios composto por cargos, funções específicas, hierarquias, tecnologias, normas, capitais simbólicos e produção organizada de agentes conjugados (BECKER, 1986). Essa disposição inicial foi posteriormente experimentada por outras agências, o que ampliou o campo no país, como atesta Julio Cosi, um dos primeiros diretores da Eclética, em depoimento a Genival Rabelo (1956): “A Eclética foi sempre uma espécie de célula-mater na propaganda. Dela saíram elementos, 
que depois de experimentados, fundaram novas agências, ampliando o campo da publicidade" (RABELO, 1956, p. 85).

Mesmo assim, as funções ainda não eram claramente definidas em cada setor e a agência operava como uma grande orientadora das atividades comerciais. Os donos da Eclética se envolviam em várias facetas do negócio do cliente em uma relação bem próxima, como no caso da fundação da grande loja de roupas A Capital, onde a Eclética procurou o local, o melhor ponto de venda e a própria instalação da loja (RABELO, 1956).

Os primeiros trabalhos de pesquisa publicitária no Brasil também aconteceram no chamado Departamento Estrangeiro da Eclética, que promoveu estudos de mercado com consumidores e anunciantes. O grande número de departamentos e a partilha de tarefas em uma agência enfatiza o caráter intrincado e multifacetado da produção de anúncios. Quanto mais robustas e sofisticadas forem as divisões de uma empresa, maior a importância do campo e de sua complexa ordem produtiva. Segundo Becker (1977a, 1977b), a emergência de um novo setor reorganiza as relações de poder e as ordenações hierárquicas de todo o conjunto. As divisões traçadas pelas agências norte-americanas desde a segunda metade do século XIX prevaleceram como modelos de estrutura interna formal não apenas para o Brasil, como também para a maioria das agências de propaganda do mundo.

A Eclética pretendeu estabelecer uma sequência de ações coordenadas para desenvolver os anúncios. Assim, pesquisa e levantamento de dados passam a fazer parte do conjunto de práticas de valorização do trabalho realizado e legitimação social do campo. Para Becker (1977a), o tempo e a prática transformam as atividades em um modelo de gestão rotineiro, pois uma vez aprendidas e realizadas com eficiência pelos diferentes profissionais em seus papéis específicos, criam uma "realidade" particular daquela profissão. As práticas se repetem e a rotina toma forma (BECKER, 1977a). Um primeiro movimento, ao receber uma conta, passa a ser levantar informações sobre o produto, sua fabricação, principais características, finalidade, preço, distribuição, diferenças dos concorrentes e capacidade pecuniária dos clientes. O segundo movimento da rotina desse fazer publicitário seria definir o veículo capaz de alcançar os clientes que desejavam conquistar, considerando preço e local. A terceira etapa era planejar e criar os anúncios, reunindo textos e apresentação gráfica.

A interligação entre setores da agência inventa, define e consolida a ideia de ação coletiva, constrói as diferentes identidades profissionais em torno de práticas, valores e convenções partilhadas pelo campo da publicidade. Segundo a reflexão de Becker (1977b), 
esse interacionismo, no mesmo gesto, aguça o senso de pertencimento ao empreendimento coletivo e reforça o efeito de recompensa de cada agente por sua forma específica de encaixe no produto final, o anúncio como resultado palpável da ação coletiva daquele mundo. A troca dependente entre partes produz sentidos comuns do valor daquilo que é produzido coletivamente (BECKER, 1977b).

Por outro lado, essa rotina baseada em convenções bem demarcadas levou ao predomínio desproporcional da instituição sobre os processos produtivos. O esquematismo correto e meticuloso das ações combinadas também pode ser responsável por uma maior burocratização das etapas, previsibilidade de resultados e carência de inovação. A divisão de tarefas e o cumprimento de códigos disciplinares das agências, embora ainda predominantes no mercado, tem sido, por vezes, substituídos por estruturas que, ancoradas em facilidades digitais, conseguem baratear custos e agilizar resultados.

A relação com os meios - proximidades e distanciamentos negociados na definição de fronteiras profissionais entre publicitários e jornalistas - leva a Eclética a organizar os "Anúncios Classificados" do jornal $O$ Estado de S. Paulo, tendo exclusividade de publicação na nova seção. O aparecimento dessa subdivisão foi muito celebrado pela indústria e comércio e até hoje é um espaço forte no cenário da imprensa brasileira. $\mathrm{O}$ modelo já era usual nos jornais internacionais.

A ausência de reconhecimento público da profissão de publicitário naquele início de século era de tal ordem que os anunciantes escondiam as informações sobre seus negócios. Nesse processo de validação de seu próprio campo, a Eclética começa a editar o Jornal dos Jornais, com tabelas de preços, dimensões de colunas e páginas do Brasil e exterior, preço das assinaturas, tiragens e dados informativos e estatísticos sobre a imprensa em geral (RABELO, 1956). O resultado foi muito importante no sentido da legitimação, levando a empresa a lançar o Anuário da Imprensa Brasileira e a revista Propaganda, nitidamente voltada para expressar a profissão e as vantagens do aumento da publicidade para o mundo comercial (RABELO, 1956). Tais como os manuais e guias lançados pela N.Y. Ayer, as publicações produziam um "saber" e conferiram prestígio ao campo. Edições com estudos sobre os processos produtivos, organização e catalogação de informações a respeito do negócio, além de articular diferentes agentes, davam visibilidade a uma representação da profissão de publicitário que primeiro deveria ser reconhecida no universo empresarial e, mais adiante, na sociedade mais ampla. As publicações serviam de pontes estratégicas para interligar profissionais da publicidade, meios de comunicação, 
empresas e público, gerando os conteúdos de um "saber" específico e legitimando os temas do setor. Ademais, apresentar dados estatísticos do que quer que seja pode ser parte integrante de uma ideia de honestidade, sucesso, transparência e esclarecimento. A eficácia simbólica dessas publicações se coloca, portanto, como forte instrumento de validação do campo.

De uma forma ou de outra, com mais ou menos ênfase, a Eclética foi a pedra angular na organização da propaganda como negócio no Brasil, proporcionando para todos os envolvidos no processo - anunciantes, veículos, clientes, consumidores e, sobretudo, seus próprios funcionários - a percepção de um campo profissional. Ao reproduzir modelos internacionais, já relativamente legitimados, operou o início do processo de fazer a publicidade existir como tal no país. Segundo os pesquisadores Ricardo Ramos e Pyr Marcondes (1995), além da Eclética, ao fim da Primeira Guerra Mundial, o Brasil tinha outras quatro agências de propaganda: a Francisco Pettinati, a Edanée, a Valentim Haris e a Pedro Didier e Antônio Vaudagnoti. A Eclética fechou no início da década de 1960.

Rigorosamente, existem registros de agências mais antigas. Uma delas poderia ter sido a Empresa de Publicidade e Comércio, instalada em São Paulo, em 1891, de Honório da Fonseca, antigo redator do jornal Correio Paulistano (REIS, 1990). Porém, no caso, não se caracterizou como organizadora de um campo de práticas ou de um modelo de negócios que estabelecesse os parâmetros da profissão de publicitário.

Os negócios do campo publicitário no Brasil são complexos e sofisticados, com a integração de uma série de elementos, funções e regras em torno da agência. A produção de anúncios em uma empresa de publicidade, como vimos, envolve a integração de múltiplos agentes, sujeitos que "fazem coisas juntos" e interagem entre si, por meio de convenções criadas e compartilhadas, elos e tramas estabelecidos com o mundo exterior. $\mathrm{O}$ "drama da ação" se traduz como capacidade transformadora dos agentes sociais (BECKER, 1986). Portanto, o aparecimento de uma narrativa publicitária na vida social está intimamente relacionado a seus atores e ao diálogo com seu tempo. Os rituais e as estratégias de troca são preciosos elementos para a construção de cada campo como um todo, como assinala Bourdieu (1983). O anúncio é a face que se expressa publicamente da dinâmica social, e pode ser pensado considerando contextos, experiências e trajetórias de seus idealizadores. Nesse sentido, a construção de identidades profissionais em torno das empresas de publicidade criou condutas aceitáveis e legítimas para explicitar uma nova "realidade", tanto social quanto profissional (BECKER, 1977a). Dessa forma, este estudo 
examinou o processo de ações coletivas em que os atores sociais, em permanente interação, ordenam e atualizam movimentos do mundo no qual operam, sustentando, assim, suas práticas e representações na cultura e na história.

Referências

ABREU, Alzira Alves de; PAULA, Christiane Jalles de (coord.). Dicionário históricobiográfico da propaganda no Brasil. Rio de Janeiro: Editora FGV, 2007.

ALMEIDA, Luiz Pedro Moutinho de. Algumas notas biográficas sobre Fernando Pessoa. Setubal: Tip. Sado, 1954.

BARBOSA, Marialva. História cultural da imprensa: Brasil 1900-2000. Rio de Janeiro: Mauad X, 2007.

BECKER, Howard. Uma teoria da ação coletiva. Rio de Janeiro: Zahar Editores, 1977a.

BECKER, Howard. Mundos artísticos e tipos sociais. In: VELHO, Gilberto (org.). Arte e sociedade. Rio de Janeiro: Zahar editores, 1977b. p. 09-25

BECKER, Howard. Doing things together. Evanston, Illinois: Northwestern University Press, 1986.

BECKER, Howard. Uma carreira como sociólogo da música. Contemporânea. Revista de

Sociologia da UFSCar. São Carlos, v. 3, nº 1, p. 131-141, jan./jun., 2013. Disponível em: http://www.contemporanea.ufscar.br/index.php/contemporanea/article/view/129/76.

Acesso em: 30 maio 2019.

BOURDIEU, Pierre. O campo científico. In: ORTIZ, Renato (org.). Pierre Bourdieu. São Paulo: Ática, 1983. p. 122-155.

BOURDIEU, Pierre. O poder simbólico. Rio de Janeiro: Bertrand Brasil, 1998.

HOWER, Ralph M. The history of an advertising agency: N. W. Ayer \& Sons at Work, 1869-1949. Cambridge: Harvard University Press, 1978.

J. WALTER THOMPSON. History of advertising. New York, 2014. Disponível em: https://www.jwt.com/history/ Acesso em: 30 maio 2019.

KNOPLOCH, Zilda. A ideologia dos publicitários. Rio de Janeiro: Achiamé, 1980.

LÉVI-STRAUSS, Claude. Raça e história. Lisboa: Presença, 1973 [1952].

MALANGA, Eugênio. Publicidade: uma introdução. São Paulo: Atlas: 1976.

PENTEADO, Claudia. J. Walter Thompson - 75 anos de Brasil. Revista ESPM-SP, São Paulo, ano 10, v. 11, n.5, p. 106-121, set./out., 2004. Disponível em: 
http://arquivo.espm.br/revista/Setembro_2004/files/assets/basic-html/index.html\#106. Acesso em: 30 maio 2019.

PINCAS, Stéphane; LOISEAU, Marc. A history of advertising. [S.1.]: Taschen, 2008.

POLANYI, Karl. A grande transformação: as origens da nossa época. São Paulo: Elsevier-Campus, 2012 [1944].

RABELO, Genival. Os tempos heroicos da propaganda. Rio de Janeiro: Empresa Jornalística PN S/A, 1956.

RAMOS, Ricardo; MARCONDES, Pyr. 200 anos de propaganda no Brasil: do reclame ao cyber-anúncio. São Paulo: Meio e Mensagem, 1995.

REFLICTA antes. O Estado de S. Paulo, São Paulo, p. 16, 26 fev. 1925. Disponível em: https://acervo.estadao.com.br/pagina/\#!/19250226-16805-nac-0016-999-16-clas. Acesso em: 30 maio 2019. Anúncio.

REIS, Fernando. São Paulo e Rio: a longa caminhada. In: BRANCO, Renato Castelo; MARTENSEN, Rodolfo L.; REIS, Fernando (org.). História da propaganda no Brasil. São Paulo: T.A. Queiroz, 1990. p. 303-319.

ROCHA, Everardo. Magia e capitalismo. São Paulo: Brasiliense, 1985.

ROCHA, Everardo; FRID, Marina; CORBO, William. O paraíso do consumo: Émile Zola, a magia e os grandes magazines. Rio de Janeiro: Mauad X, PUC-Rio, 2016.

WAGNER, Roy. A invenção da cultura. São Paulo: Cosac Naify, 2010.

Submetido em: 30.07.2018

Aprovado em: 01.02.2019 